\title{
Recycling valuable silver from waste generated in diverse nanotemplate reactions
}

\author{
Jin-Long Wang, Zhi-Hua Wang, Jian-Wei Liu* and Shu-Hong Yu*
}

\begin{abstract}
The shape-controlled silver nanostructures have been widely used for template synthesis of metal nanostructures with desired morphologies and compositions for specific applications by galvanic replacement reaction, while the silver is sacrificed as oxidized to silver ion and abandoned as by-products. In view of the broad application prospect of the obtained metal nanostructures, the cost and environment problems after the template reactions should be taken into account for the large scale production in the future. To solve this problem, we conceptually demonstrate that the wasted $\mathrm{AgCl}$ generated from the template reactions can be easily recycled for the synthesis of valuable Ag nanowires. As representative examples, the average recovery of silver can be about $69.8 \%-84.6 \%$ after the template synthesis of $\mathrm{Au} / \mathrm{Pt}$ nanostructures. The resynthesized Ag nanowires show uniform size distribution and excellent physical and chemical properties for the fabrication of transparent electrode and template synthesis.
\end{abstract}

Keywords: silver nanostructures, templating synthesis, metal nanostructures, waste, recycling, silver nanowires

\section{INTRODUCTION}

Metal nanomaterials with well-defined structures have received increasing attention in recent years due to their fascinating performance in various fields such as optoelectronics, catalysis, sensing, biomedicine and so on [1-5]. In order to tailor their properties for specific applications, many studies have been focused on fabricating metal nanostructures with controlled parameters especially the shape and composition [6-10]. Compared with the solid sample, the porous or hollow metal nanostructures are lower in density and higher in surface area and proved to be more economically viable and efficient in properties (e.g., catalysis and sensing) $[11,12]$. Among various methods, the template-directed synthesis has been demonstrated as the most straightforward and commonly used method for the synthesis of porous or hollow metal nanostructures because of its easy scalability and high structural controllability $[13,14]$. Despite the advantages, the templates during the reactions are always etched out and wasted. In view of the broad application prospect of the obtained metal nanostructures, the cost and environmental problems after the template reactions should be taken into account for the large scale production in the future especially when the templates are expensive or toxic [15].

Silver nanostructures as templates for the synthesis of multifunctional porous metal nanostructures (such as $\mathrm{Au}$ nanostructures) were firstly reported by Xia's group $[9,16]$, and since then the template synthesis using silver nanostructures as templates has been successfully extended to be a particularly effective and versatile synthesis strategy due to the easy control of the composition, internal structure, and morphology of the resultant nanostructures [17-27]. However, when considering the cost and wide applications of electronics, surface plasmonics, surface-enhanced Raman scattering spectroscopy (SERS) and chemical sensing for the silver itself [28], it will be a waste when the silver nanostructures are sacrificed after the template synthesis which usually transform to $\mathrm{AgCl}$ precipitate and are abandoned as by-products. Although the element of silver has high price as a noble metal, how to deal with the by-products of $\mathrm{AgCl}$ during the experiments has always been ignored over the past years.

Herein, we first report a general strategy for synthesis of Ag nanowires (NWs) by recycling the valuable silver from wasted $\mathrm{AgCl}$ solid generated in diverse nanotemplate reactions (e.g., template synthesis of $\mathrm{Au} / \mathrm{Pt}$ hollow nanostructures) (Scheme 1). This strategy can make the wasted $\mathrm{AgCl}$

Division of Nanomaterials \& Chemistry, Hefei National Laboratory for Physical Sciences at the Microscale, Collaborative Innovation Center of Suzhou Nano Science and Technology, Department of Chemistry, CAS Center for Excellence in Nanoscience, Hefei Science Center of CAS, University of Science and Technology of China, Hefei 230026, China

*Corresponding authors (emails: shyu@ustc.edu.cn (Yu SH); jwliu13@ustc.edu.cn (Liu JW)) 


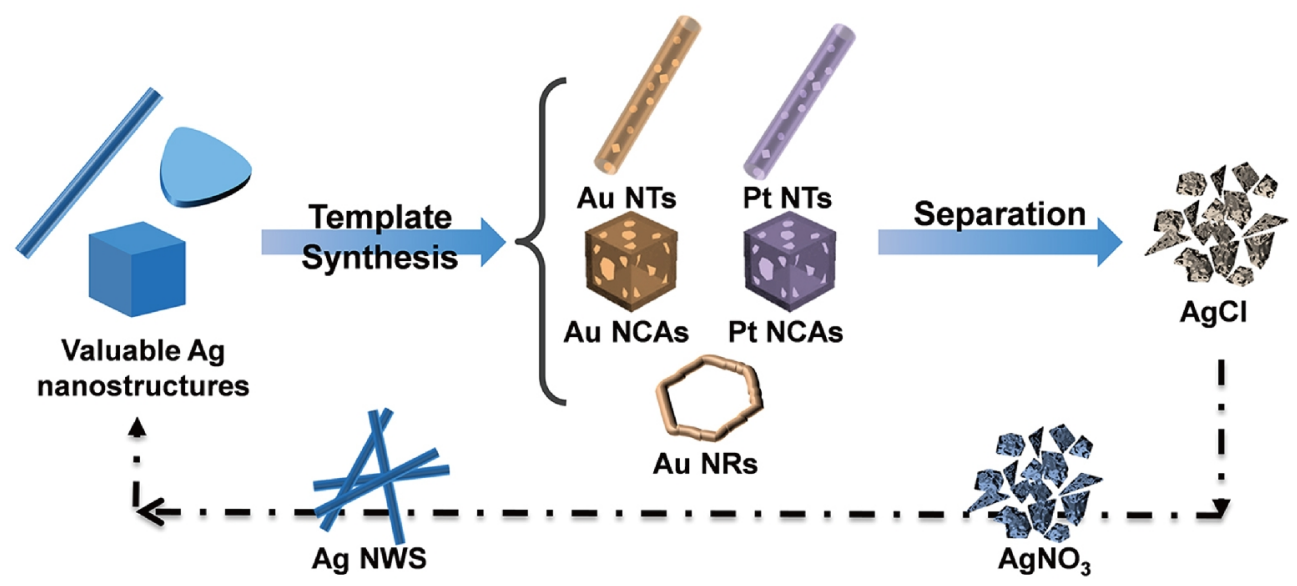

Scheme 1 Illustration of recycling the valuable silver from wasted AgCl solid generated in diverse nanotemplate reactions to synthesize Ag NWs.

into valuable silver nanostructures and pave the way for the large-scale production of multiple metal nanostructures that were template synthesized from silver nanostructures with much less cost and waste. Compared with the content of the sacrificed silver during the template reactions, the average recovery of the silver recycled for the synthesis of $\mathrm{Ag} \mathrm{NWs}$ can be about $69.8 \%-84.6 \%$. In addition, the reproduced Ag NWs show uniform size distribution with diameter of $\sim 44 \mathrm{~nm}$ and are still with excellent physical and chemical properties for the fabrication of transparent electrode and various template syntheses.

\section{EXPERIMENTAL SECTION}

\section{Materials}

$\mathrm{AgNO}_{3}$, ethylene glycol, glycerol, $\mathrm{HAuCl}_{4} \cdot 4 \mathrm{H}_{2} \mathrm{O}$, $\mathrm{H}_{2} \mathrm{PtCl}_{6} \cdot 6 \mathrm{H}_{2} \mathrm{O}$, poly(vinyl pyrrolidone) (PVP, $M_{W} \approx$ 40,000), $\mathrm{Na}_{3} \mathrm{CA}, \mathrm{NaBH}_{4}, \mathrm{Na}_{2} \mathrm{~S}$, L-ascorbic acid, $\mathrm{NaCl}$, ammonium hydroxide (28 wt.\%) and hydrazine hydrate $(85$ wt.\%) were all purchased from Shanghai Chemical Reagent Co. Ltd. All chemicals were of analytical grade and were used as received without further purification except the ethylene glycol (EG) which was refluxed at $140^{\circ} \mathrm{C}$ for $3-5 \mathrm{~h}$.

\section{Instruments}

Transmission electron microscopy (TEM) were carried out on a commercial JEOL-7650 transmission electron microscope operated at an accelerating voltage of 100 $\mathrm{kV}$. Scanning electron microscopy (SEM) was carried out on a Zeiss Supra 40 field-emission scanning microscope operated at $5 \mathrm{kV}$. The X-ray diffraction patterns (XRD) were measured on a Philips X'Pert Pro Super X-ray diffractometer equipped with graphite-monochromatized $\mathrm{Cu} \mathrm{Ka}$ radiation. UV-vis spectra were recorded on
UV-2501PC/2550 at room temperature (Shimadzu Corporation, Japan). The content of element silver was measured by inductively coupled plasma (ICP) mass spectrometry (Plasma Quad 3, America).

\section{Synthesis of Ag nanocubes}

In a typical synthesis, $12 \mathrm{~mL}$ EG was heated at $150^{\circ} \mathrm{C}$ in a $25 \mathrm{~mL}$ glass vial. After about $20 \mathrm{~min}, 3 \mathrm{~mL}$ and $1 \mathrm{~mL} \mathrm{EG}$ solutions containing $\mathrm{AgNO}_{3}\left(48 \mathrm{mg} \mathrm{mL}^{-1}\right)$ and $\mathrm{PVP}\left(M_{w} \approx\right.$ $40,000)\left(20 \mathrm{mg} \mathrm{mL}^{-1}\right)$ were sequentially injected and stirred for $9 \mathrm{~min}$, and then $0.16 \mathrm{~mL}$ EG solution containing $\mathrm{Na}_{2} \mathrm{~S}$ $\left(3 \mathrm{mmol} \mathrm{L}{ }^{-1}\right)$ was quickly injected. After $10-15 \mathrm{~min}$, the color of the solution changed to opalescent ruddy-brown and concurrently became opaque indicating the formation of Ag nanocubes [29].

\section{Synthesis of Ag NWs}

In a typical synthesis, $5.86 \mathrm{~g}$ PVP was added to $190 \mathrm{~mL}$ of glycerol in a $500 \mathrm{~mL}$ three-necked, round bottle flask and heated at $110^{\circ} \mathrm{C}$ to get a homogeneous solution. After cooling to room temperature, $1.58 \mathrm{~g} \mathrm{AgNO}_{3}$ was added to the solution. Then the solution was heated from room temperature to $210^{\circ} \mathrm{C}$ in $30 \mathrm{~min}$ with slow stirring. When the temperature reached at about $60^{\circ} \mathrm{C}, \mathrm{NaCl}$ solution $(59 \mathrm{mg}$ of $\mathrm{NaCl}$ dissolving in $0.5 \mathrm{~mL}$ of deionized water and $10 \mathrm{~mL}$ of glycerol) was added to the flask. The heating stopped immediately as soon as the temperature reached at $210^{\circ} \mathrm{C}$, and $200 \mathrm{~mL}$ deionized water was added to the solution. The solution was kept undisturbed for $24 \mathrm{~h}$ to remove $\mathrm{Ag}$ nanoparticles from the NWs [30].

\section{Synthesis of Ag nanoplates}

In a typical synthesis, the silver seeds were firstly synthesized as follows: $110 \mathrm{~mL}$ of aqueous solution containing 
$\mathrm{AgNO}_{3}\left(0.11 \mathrm{mmol} \mathrm{L}{ }^{-1}\right)$ and $\mathrm{Na}_{3} \mathrm{CA}\left(2.05 \mathrm{mmol} \mathrm{L}^{-1}\right)$ was prepared. Under magnetic stirring, $3 \mathrm{~mL}$ aqueous solution containing $5 \mathrm{mmol} \mathrm{L}^{-1} \mathrm{NaBH}_{4}$ was added to the solution in one go and the mixture was stirred for $10 \mathrm{~min}$. This seed solution was then aged at room temperature for $5 \mathrm{~h}$ prior to future use. Then silver nanoplates were synthesized as follows: $92.5 \mathrm{~mL}$ of deionized water was mixed with 10 $\mathrm{mL}$ aqueous $\mathrm{AgNO}_{3}\left(5 \mathrm{mmol} \mathrm{L}^{-1}\right), 7.5 \mathrm{~mL}$ aqueous PVP $\left(0.7 \mathrm{mmol} \mathrm{L}^{-1}\right.$ in terms of the repeating unit), $7.5 \mathrm{~mL}$ aqueous $\mathrm{Na}_{3} \mathrm{CA}\left(30 \mathrm{mmol} \mathrm{L}^{-1}\right)$, and $6.4 \mathrm{~mL}$ of the as-prepared seed solution, followed by dropping into $62.5 \mathrm{~mL}$ aqueous L-ascorbic acid $\left(1 \mathrm{mmol} \mathrm{L}^{-1}\right)$ under magnetic stirring. After $15 \mathrm{~min}$, the colour of the solution became unchanged indicating the formation of nanoplates [31].

\section{Synthesis of $\mathrm{Au} / \mathrm{Pt}$ nanostructures}

All the Ag nanostructures were centrifuged and washed with water for twice and then dispersed into deionized water containing $1 \mathrm{mg} \mathrm{mL}^{-1} \mathrm{PVP}$ (the concentration of the $\mathrm{Ag}$ nanostructures were about $0.05 \mathrm{mg} \mathrm{mL}^{-1}$ ) and were heated to boiling for $10 \mathrm{~min}$ with vigorous stirring, then different volumes of $1 \mathrm{mmol} \mathrm{L}^{-1} \mathrm{HAuCl}_{4}$ and $0.2 \mathrm{~mL}\left(1 \mathrm{mmol} \mathrm{L}^{-1}\right)$ $\mathrm{H}_{2} \mathrm{PtCl}_{6}$ (the molar ratio of $\mathrm{Au} / \mathrm{Pt}$ to $\mathrm{Ag}$ was $1: 3$ and $1: 4$ ) were dropped to the solutions at the rate of $45 \mathrm{~mL} \mathrm{~h}^{-1}$. After another $10 \mathrm{~min}$, the color of the solution became stable, indicating the formation of $\mathrm{Au} / \mathrm{Pt}$ nanostructures [23,32-35].

\section{Recycle the silver after the template synthesis}

In a typical process, $(0.6 \mathrm{~mL})$ ammonium hydroxide $(28$ wt.\%) was dropped to $10 \mathrm{~mL}$ deionized water containing the products until the $\mathrm{AgCl}(0.034 \mathrm{~g})$ was fully dissolved to the transparent Tollens' Reagent and centrifuged from the valuable metal nanostructures, then $(0.2 \mathrm{~mL})$ hydrazine hydrate (85 wt.\%) was added to the solution of the separated Tollens' Reagent to get the Ag particles. After centrifugation, $(0.1 \mathrm{~mL}) \mathrm{HNO}_{3}(65 \mathrm{wt} . \%)$ was added to Ag precipitate in $25 \mathrm{~mL}$ round-bottom flask to form $\mathrm{AgNO}_{3}$ and dried at $80^{\circ} \mathrm{C}$ for the further application of synthesis Ag NWs.

\section{Synthesis of Ag NWs from recycled silver}

The silver NWs were synthesized by a modified polyol process. Typically, $0.125 \mathrm{~g}$ PVP was added to $8 \mathrm{~mL}$ glycerol in a round-bottom flask and heated to $100^{\circ} \mathrm{C}$ until the PVP was fully dissolved. After cooling to room temperature, 40 $\mathrm{mg} \mathrm{AgNO}_{3}$ was added and then $2 \mathrm{~mL}$ glycerol containing $4 \mathrm{mg} \mathrm{NaCl}$ dissolved in $50 \mu \mathrm{L}$ deionized water was added. The solution was then heated at $180^{\circ} \mathrm{C}$ for $5 \mathrm{~h}$ for the growth of Ag NWs [30,36].

\section{RESULTS AND DISCUSSION}

As chemical template, Ag nanostructures [28] have been widely studied for the synthesis of metal nanostructures with well-controlled sizes and shapes because the physicochemical properties of the metals are strongly dependent on their size, shape, and morphology [37]. Three kinds of Ag nanostructures that are nanocubes (NCs), NWs and nanoplates (NPs) were selected as templates to synthesize $\mathrm{Au} / \mathrm{Pt}$ nanostructures for the study of recycling $\mathrm{AgCl}$ to the valuable Ag NWs in the practice.

The gold and platinum hollow nanostructures with wide applications in sensing and catalysts are commonly synthesized using Ag nanostructures as templates by the galvanic replacement reactions because of the more positive reduction potential of the $\mathrm{AuCl}_{4}{ }^{-} / \mathrm{Au}\left(\mathrm{PtCl}_{6}{ }^{2-} / \mathrm{Pt}\right)$ than $\mathrm{AgCl} / \mathrm{Ag}$. After the galvanic replacement reactions, silver was oxidized to $\mathrm{Ag}^{+}$and quickly reacted with $\mathrm{Cl}^{-}$to form the precipitate of AgCl. Figs 1a, d and g are the typical TEM images of the Ag NCs, NWs and NPs synthesized according to previous reports [29-31]. For the synthesis of hollow metal nanostructures, the templates of silver nanostructures were first added to the boiling water for ten minutes with vigorous stirring to form a homogeneous suspension, and then the desired noble metal salts (e.g., $\mathrm{HAuCl}_{4}$ and $\mathrm{H}_{2} \mathrm{PtCl}_{6}$ ) were titrated to the solution at the rate of $45 \mathrm{~mL} \mathrm{~h}^{-1}$. Using the Ag NCs as a template, the Au and Pt nanocages (NCAs) were synthesized as shown in Figs $1 \mathrm{~b}$ and $\mathrm{c}$ through the galvanic replacement reactions $[23,32]$. Besides, the $\mathrm{Au}, \mathrm{Pt}$ nanotubes (NTs) and Au nanorings (NRs) (Figs le, $\mathrm{f}$ and $\mathrm{h}$ ) were also synthesized using the Ag NWs and NPs as templates [33-35]. As shown by the TEM and SEM images (Figs S1a-h), the most component of silver was etched away and translated to the Pt or Au porous and hollow nanostructures, which were also characterized by XRD patterns (Fig. S2). The change of the UV-vis absorption spectra and color of the suspension between the silver and metal $(\mathrm{Au} / \mathrm{Pt})$ nanostructures shown in Supplementary information (Fig. S3) indicates the different optical properties of the products. The amounts of the Ag nanostructures before and after different template reactions were recorded by the inductively coupled plasma mass spectrometry (ICP) as shown in Supplementary information (Table S1). Different from the previous reports, $\mathrm{AgCl}$ produced in the experiments was collected and Fig. 1i shows the typical $\mathrm{AgCl}$ suspension recycled for the synthesis of Ag NWs.

Synthesis of Ag NWs has been extensively studied because of the excellent electrical conductivity and mechanical robustness for wider applications of electronics $[28,36,38-40]$. In the most synthesis strategies, $\mathrm{AgNO}_{3}$ was 

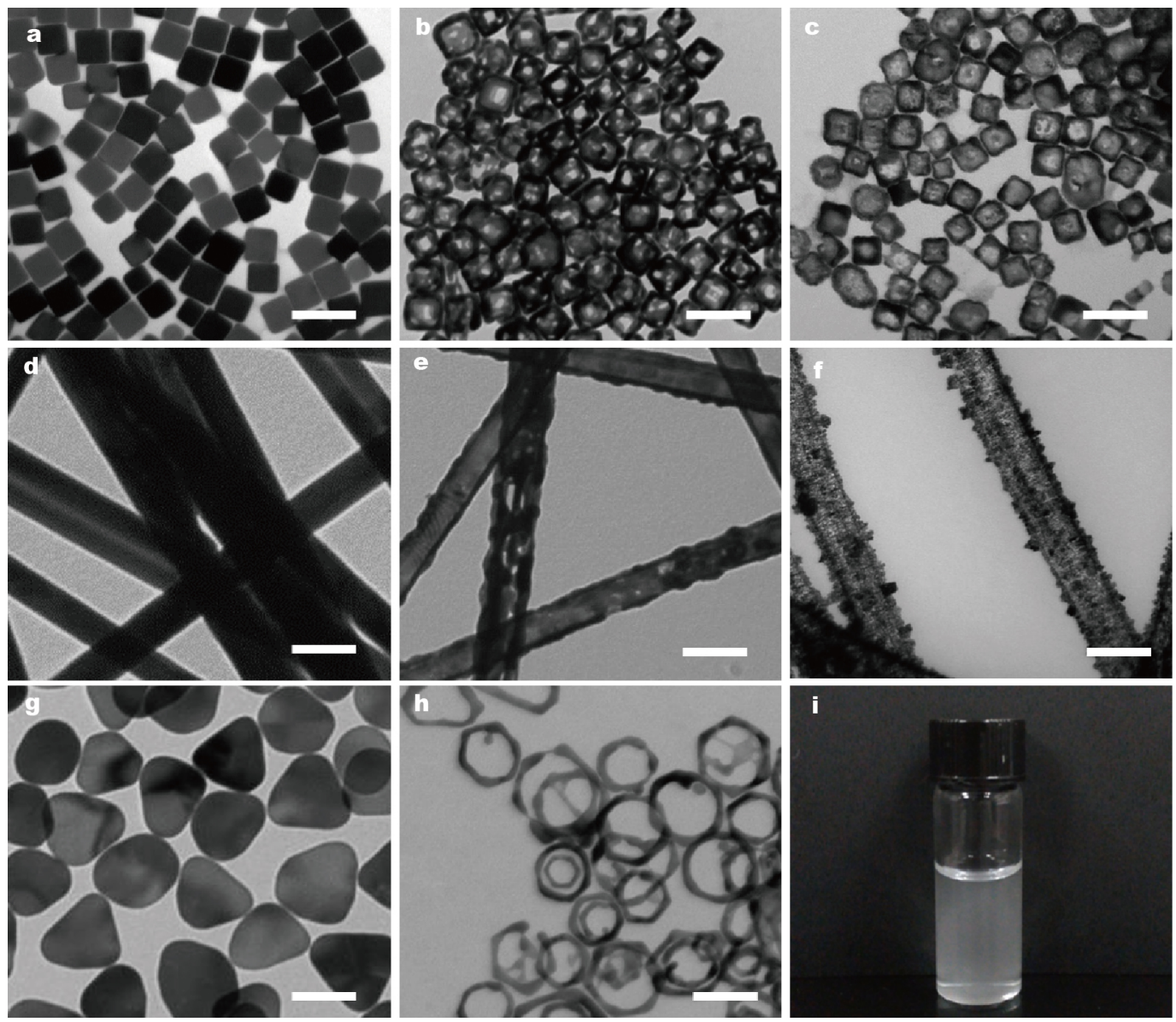

Figure 1 (a-c) TEM images of the Ag NCs, Au NCAs and Pt NCAs. (d-f) TEM images of the Ag NWs, Au NTs and Pt NTs. (g, h) TEM images of the $\mathrm{Ag}$ NPs and Au NRs. (i) Digital photograph of the $\mathrm{AgCl}$ suspension recycled from the template synthesis. The scale bar in $(\mathrm{a}-\mathrm{h})$ is $100 \mathrm{~nm}$.

reported as the most commonly used precursor for the synthesis of Ag NWs. Based on the previous reports [30,36], we synthesized Ag NWs using the AgCl precipitate as the starting precursor with several chemical transformation processes introduced. Although it seems more complicated and unnecessary for the synthesis of Ag NWs, this strategy actually resolves the problem existing in the template synthesis that $\mathrm{AgCl}$ usually is washed away using saturated $\mathrm{NaCl}$ solution and abandoned as by-product. The typical process for the synthesis of Ag NWs and the chemical transformation processes can be described as follows:

$$
\begin{gathered}
\mathrm{AgCl}+2 \mathrm{NH}_{3} \cdot \mathrm{H}_{2} \mathrm{O} \rightarrow \mathrm{Ag}\left(\mathrm{NH}_{3}\right)_{2}^{+}, \\
\mathrm{Ag}\left(\mathrm{NH}_{3}\right)_{2}^{+}+\mathrm{N}_{2} \mathrm{H}_{4} \cdot \mathrm{H}_{2} \mathrm{O} \rightarrow \mathrm{Ag}, \\
\mathrm{Ag}+\mathrm{HNO}_{3} \rightarrow \mathrm{AgNO}_{3}, \\
\mathrm{AgNO}_{3}+\mathrm{PVP}+\text { glycerol }+\mathrm{NaCl} \rightarrow \mathrm{Ag}(\mathrm{NWs}) .
\end{gathered}
$$

Figs 2a and S4a show the typical XRD pattern of $\mathrm{AgCl}$ that was separated from the products after the template reactions of synthesis metal nanostructures by precipitation process. According to the Reactions (1-3), the ammonium hydroxide was added to the $\mathrm{AgCl}$ suspension to form silver-ammonia solution, then it was reduced to silver particles (Figs $2 \mathrm{~b}$ and $\mathrm{S} 4 \mathrm{~b}$ ) by adding the appropriate amount of hydrazine hydrate as reducing agent, and $\mathrm{AgNO}_{3}$ (Figs $2 \mathrm{c}$ and $\mathrm{S} 4 \mathrm{c}$ ) was formed by adding concentrated $\mathrm{HNO}_{3}$ to the centrifuged silver particles. Finally, the Ag NWs can be easily synthesized by a modified polyol method as described in Reaction (4) (the details are given in the experiment part).

However, the by-product of $\mathrm{AgCl}$ produced after the template reactions cannot be fully separated through the precipitation process from the products owing to the sedimentation and adsorbing with the porous products. To overcome this problem, we first centrifuged the products and $\mathrm{AgCl}$ together to remove the impurities such as the unreacted noble metal salts in the solution, and then added the 

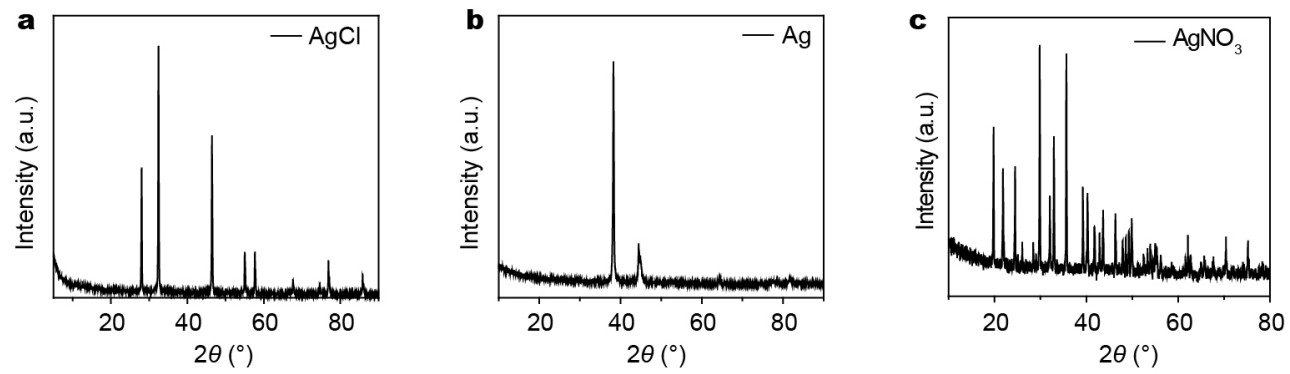

Figure 2 XRD patterns of the recycled (a) $\mathrm{AgCl}$ after the template reactions; (b) $\mathrm{Ag}$; (c) $\mathrm{AgNO}_{3}$.

dilute solution of ammonium hydroxide to the precipitate to dissolve $\mathrm{AgCl}$ from the products. It has been reported [41] that the ammonium hydroxide solution can etch Ag to silver-ammonia solution when exposed to the oxygen, which might involve the dealloying process that does not exist when using the saturated sodium chloride solution to wash the precipitate of $\mathrm{AgCl}$ as previous reports. In this report, we bubbled nitrogen to the suspension of the precipitate to avoid the attack of the oxygen. Figs $3 a-c$ are typical TEM images and UV-vis spectra of Ag NWs before and after the immersion of ammonium hydroxide for two hours and show that only the end places of the Ag NWs were slightly etched with little change of the UV-vis absorption peak, which might be caused by the pre-oxidation of the Ag NWs during the synthesis or transferring process. In addition, the impact of the ammonium hydroxide solution on the metal nanostructures of Au NTs has also been studied. The TEM images and UV-vis spectra shown in Figs
$3 \mathrm{~d}-\mathrm{e}$ indicate that there is almost no change in both morphology and UV-vis absorption peaks of the Au NTs even after the immersion of ammonium hydroxide solution for two hours. These results indicate that the employing of ammonium hydroxide solution to improve the recycle ratios of silver during the recycling process has almost no impact on the products when avoiding the exposure to oxygen.

Fig. 4a shows the in-situ process for the synthesis of Ag NWs from solid AgCl. Firstly, ammonium hydroxide was added to the $\mathrm{AgCl}$ suspension to form clear silver-ammonia solution, then it was reduced to silver particles by adding appropriate amount of hydrazine hydrate as reducing agent, and finally $\mathrm{AgNO}_{3}$ was formed by adding the concentrated $\mathrm{HNO}_{3}$ to the centrifuged silver particles. The Ag NWs can be easily obtained by a modified polyol method heated at $180^{\circ} \mathrm{C}$ for $5 \mathrm{~h}$. TEM and XRD characterization show that with the addition of $\mathrm{NaCl}$, some $\mathrm{AgCl}$ nanoparticles still exist in the products observed (Fig. S5),
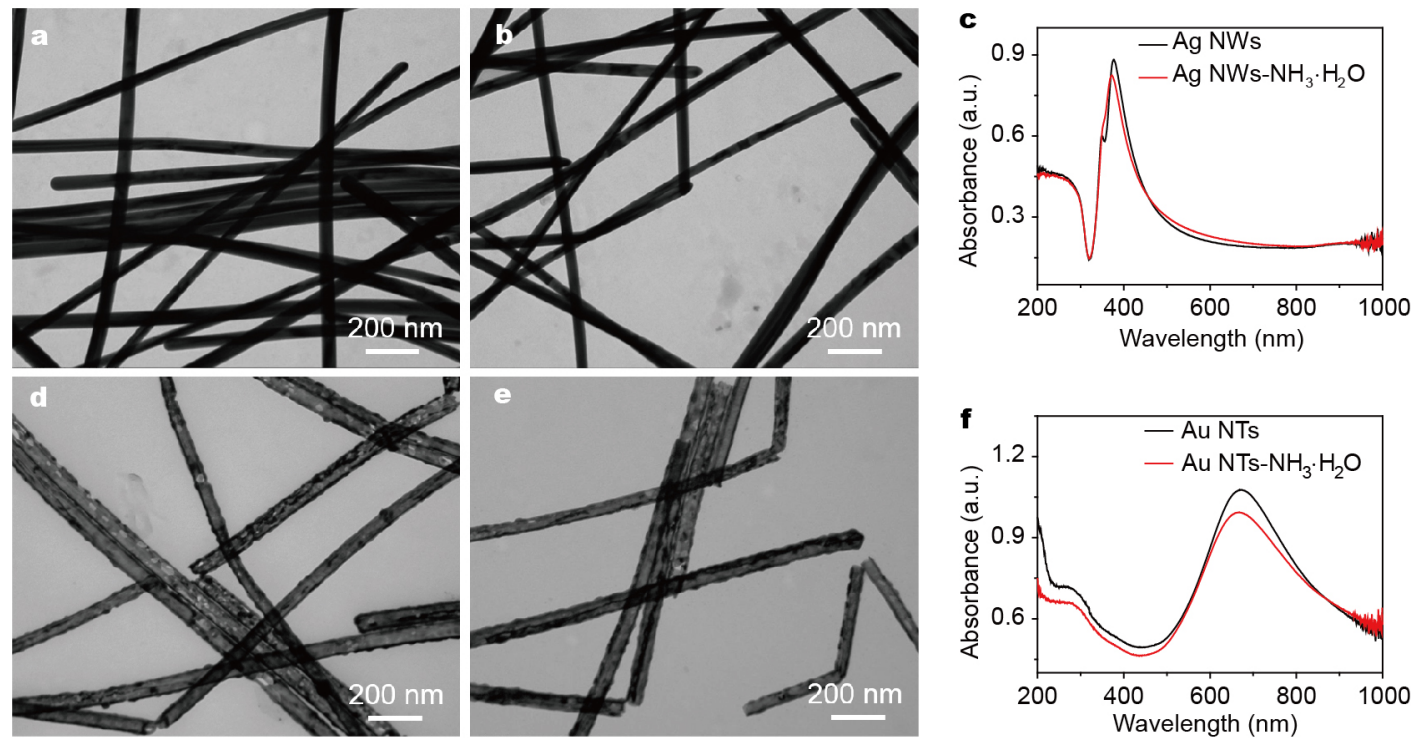

Figure 3 TEM images of Ag NWs before (a) and after (b) immersing with ammonium hydroxide; (c) UV-vis spectra of the Ag NWs before and after immersion in solution of ammonium hydroxide; (d) and (e) TEM images of Au NTs before and after immersion with ammonium hydroxide; (f) UV-vis spectra of the Au NTs before and after immersion in solution of ammonium hydroxide. 


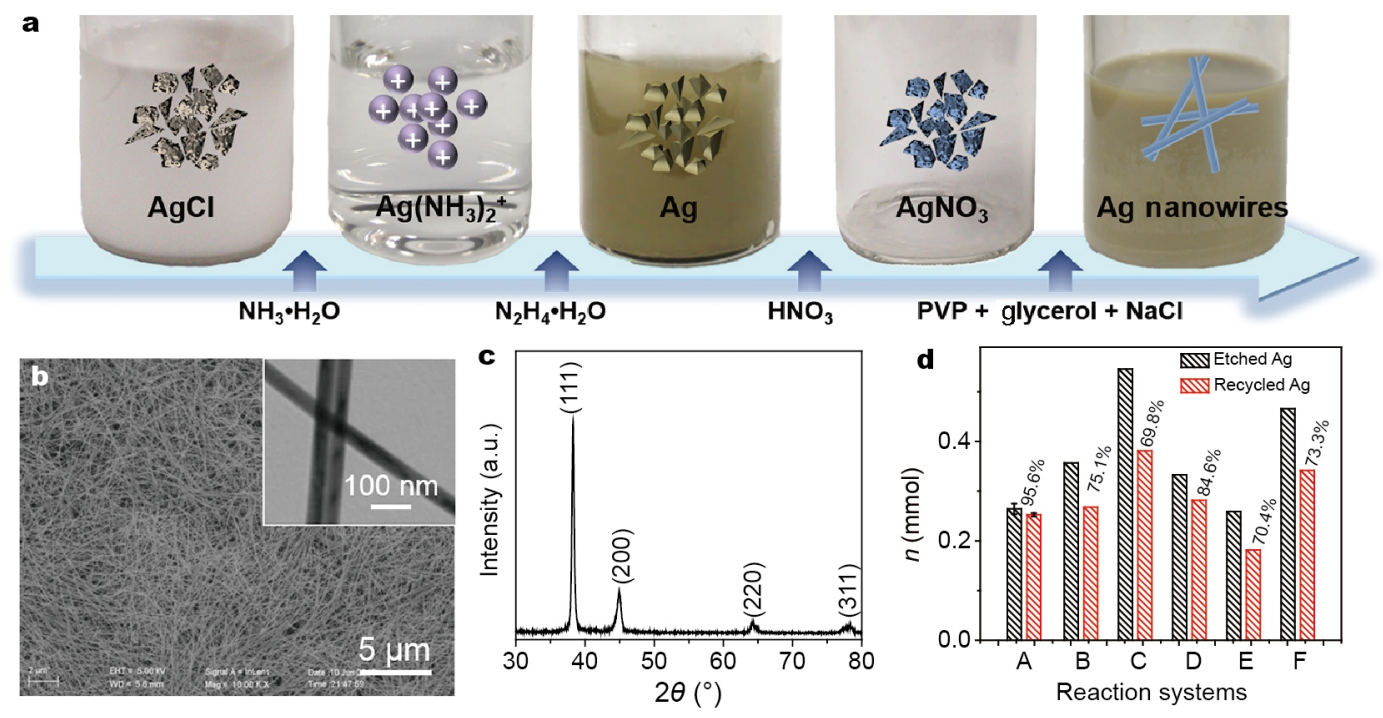

Figure 4 (a) The in-situ process for the synthesis of Ag NWs from wasted AgCl. (b) SEM image of the Ag NWs, the inset is the TEM image of the Ag NWs. (c) XRD pattern of the Ag NWs. (d) Recycle ratios of different reaction systems. A: $\mathrm{AgNO}_{3}+\mathrm{NaCl}, \mathrm{B}: \mathrm{Ag} \mathrm{NCs}+\mathrm{HAuCl}_{4}, \mathrm{C}: \mathrm{Ag} \mathrm{NCs}+\mathrm{H}_{2} \mathrm{PtCl}{ }_{6}$, D: Ag NPs $+\mathrm{HAuCl}_{4}, \mathrm{E}: \mathrm{Ag} \mathrm{NWs}+\mathrm{HAuCl}_{4}, \mathrm{~F}: \mathrm{Ag} \mathrm{NWs}+\mathrm{H}_{2} \mathrm{PtCl}_{6}$.

which can be easily washed away with dilute solution of ammonium hydroxide. Figs $4 \mathrm{~b}$ and the inset show the typical SEM and TEM images of the purified Ag NWs suggesting the uniform size of NWs ( 44 $\mathrm{nm}$ in diameter with fifty NWs statistic in Fig. S6). Fig. 4c is the XRD pattern of the resynthesized Ag NWs, showing good agreement with the standard literature data of silver (JCPDF card number: 04-0783) without any impurities. Before each synthesis process, the content of the silver was first confirmed by ICP to ensure that the raw material with appropriate ratios $\left(m\left(\mathrm{AgNO}_{3}\right): m(\mathrm{NaCl}): m(\mathrm{PVP}): V(\right.$ glycol $)=40 \mathrm{mg}: 4 \mathrm{mg}: 125$ $\mathrm{mg}: 8 \mathrm{~mL}$ ) in the synthesis process. The recycling rate of the different systems for template synthesis was characterized by the ICP as shown in Fig. 4d. Compared with silver $(100 \%)$ that was etched out during the template reactions, the relative contents of the recycled silver were about $95.6 \%$, $75.1 \%, 69.8 \%, 84.6 \%, 70.4 \%, 73.3 \%$ for different systems of synthesis $\mathrm{AgCl}\left(\mathrm{AgNO}_{3}+\mathrm{NaCl}\right), \mathrm{Au} \mathrm{NCAs}(\mathrm{Ag} \mathrm{NCs}+$ $\mathrm{HAuCl}_{4}$ ), Pt NCAs (Ag NCs $+\mathrm{H}_{2} \mathrm{PtCl}_{6}$ ), Au NRs (Ag NPs $\left.+\mathrm{HAuCl}_{4}\right), \mathrm{Au} \mathrm{NTs}\left(\mathrm{Ag} \mathrm{NWs}+\mathrm{HAuCl}_{4}\right)$, and Pt NTs (Ag $\mathrm{NWs}+\mathrm{H}_{2} \mathrm{PtCl}_{6}$ ). More than ten pots of the same template reactions were carried out to recycle silver for one-pot synthesis of Ag NWs, in view of that one pot of the template reaction had much less silver. Besides, collecting silver from more experiments at the same conditions also avoids the statistics deviation for the same template reactions. The reason for the high recycle ratio of the system for the synthesis of $\mathrm{AgCl}$ was that the reaction was only carried out in $10 \mathrm{~mL}$ aqueous solution with $33.5 \mathrm{mg} \mathrm{AgCl}$, meaning that much less $\mathrm{AgCl}$ was dissolved in the solution and less centrifugation process. The loss in yield (about 15-30\%) during each recycle process was mainly caused by the separation steps and the partial dissolution of $\mathrm{AgCl}$ in the reaction solution that could not fully precipitated by centrifugation as more aqueous solution (about $800 \mathrm{~mL}$ for $33.5 \mathrm{mg} \mathrm{AgCl}$ ) were involved in the reactions.

Recent studies of transparent electrodes revealed that silver NWs have led the way for the brittle indium tin oxides (ITO) replacement due to their intriguing electrical and optical properties. To verify the electrical performance of the Ag NWs reproduced in this report, the flexible transparent electrode was fabricated by spray-coating method according to the previous report [42]. Besides, the silver NWs as unique templates for synthesizing one dimensional (1D) metal nanostructures with novel functionalities have also been performed. Fig. 5 a depicts the strategy for the quality evaluation of the reproduced Ag NWs. For the fabrication of transparent electrode, the Ag NWs were first dispersed in ethanol solution and then spray-coated on a flexible polyethylene terephthalate (PET) substrate that anchored on a $140^{\circ} \mathrm{C}$ hotplate using a commercial airbrush (HD-130). Fig. $5 \mathrm{~b}$ shows the representative SEM image, indicating the uniformity of silver nanowire networks. The optical transmittance and sheet resistance were measured with an average value of $85 \%$ and $30 \Omega$ /sq for five different spray coated films as shown in Fig. 5c. As unique templates for 1D nanostructures, Ag NWs reproduced from the template synthesis were reused to template synthesize the core-shell 
a<smiles>[111In]</smiles>
Ag NWs Using as templates $1 / 2 y$

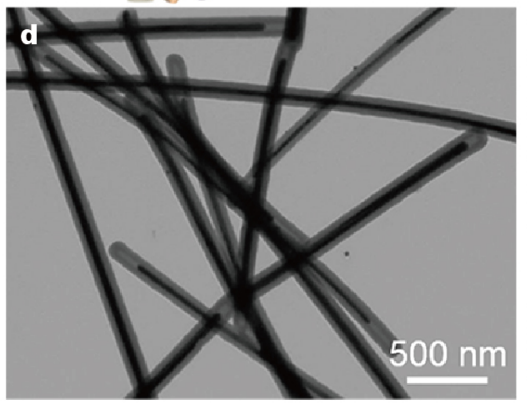

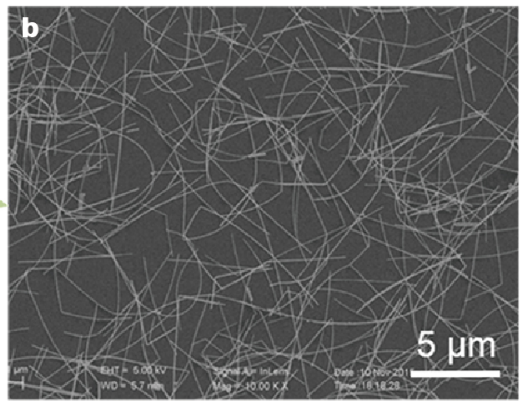
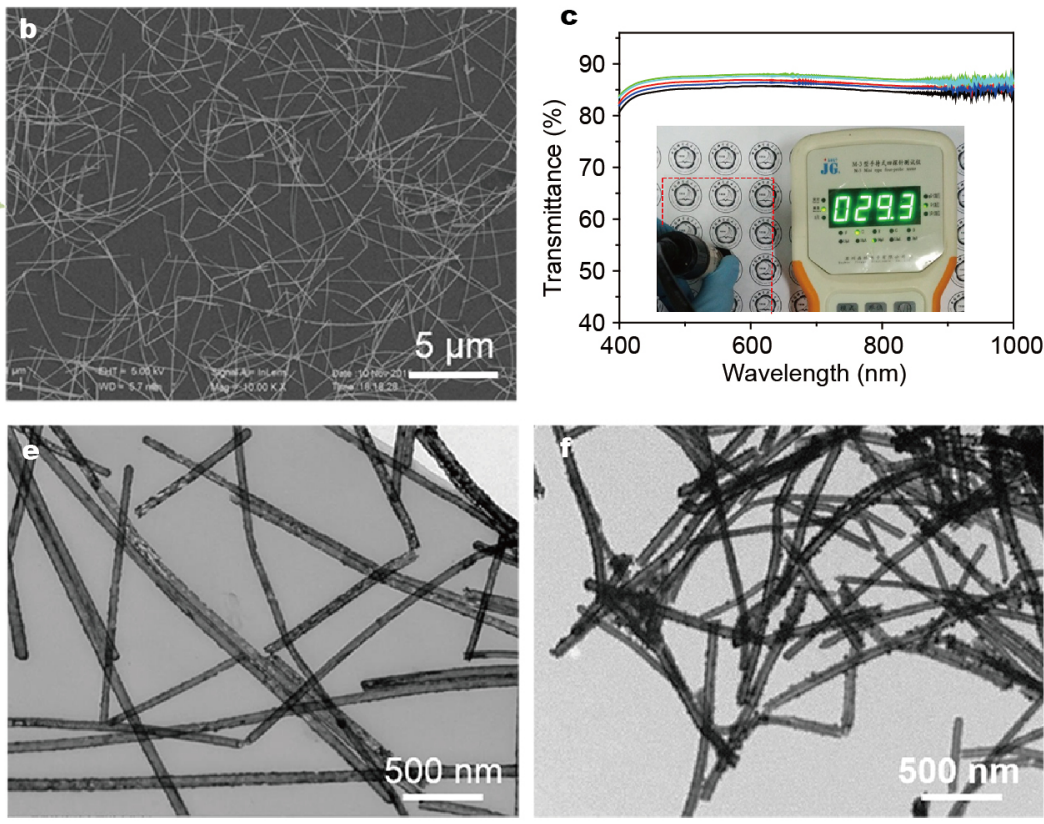

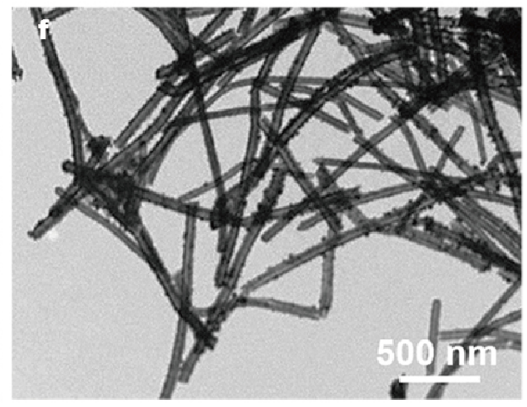

Figure 5 (a) Schematic illustration of the Ag NWs used for transparent electrodes and template synthesis. (b) SEM image of the Ag NW networks fabricated by spray-coating. (c) The transmittance spectra of five different Ag NW transparent electrode films. The inset is the sheet resistance of one

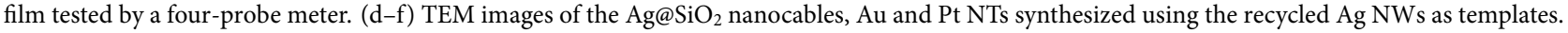

structure of $\mathrm{Ag} @ \mathrm{SiO}_{2}$ nanocables [41] (Fig. 5d) and hollow nanostructures of Au/Pt NTs (Figs $5 \mathrm{e}-\mathrm{f}$ ) with uniform morphologies. These results indicate that the Ag NWs reproduced from the template synthesis have both good physical and chemical properties for the electrodes fabrication and template synthesis.

\section{CONCLUSIONS}

In summary, we reported a general strategy to recycle valuable silver from wasted $\mathrm{AgCl}$ solid generated in diverse nanotemplate reactions. Remarkably, the by-product of $\mathrm{AgCl}$ for the synthesis of $\mathrm{Ag}$ NWs can be transferred to $\mathrm{AgNO}_{3}$ by several chemical transformations. To improve the recycle ratio of the silver, ammonium hydroxide was used to dissolve the $\mathrm{AgCl}$ that cannot be fully separated from the porous and hollow metal nanostructures by centrifugation. The resynthesized Ag NWs show uniform size distribution with excellent physical and chemical properties, which can be used for the fabrication of transparent electrode and various template syntheses. Moreover, the present work will pave the way for the large scale production of multiple metal nanostructures that are template synthesized from silver nanostructures with much less cost and waste.

Received 7 June 2016; accepted 27 June 2016; published online 20 July 2016
1 Maier SA, Brongersma ML, Kik PG, et al. Plasmonics-a route to nanoscale optical devices. Adv Mater, 2001, 13: 1501-1505

2 Habas SE, Lee H, Radmilovic V, et al. Shaping binary metal nanocrystals through epitaxial seeded growth. Nat Mater, 2007, 6: 692-697

3 Skrabalak SE, Chen J, Au L, et al. Gold nanocages for biomedical applications. Adv Mater, 2007, 19: 3177-3184

4 Jain PK, Huang X, El-sayed IH, et al. Noble metals on the nanoscale: optical and photothermal properties and some applications in imaging, sensing, biology, and medicine. Acc Chem Res, 2008, 41: 1578-1586

5 Xiong Y, Xia Y. Shape-controlled synthesis of metal nanostructures: the case of palladium. Adv Mater, 2007, 19: 3385-3391

6 Burda C, Chen X, Narayanan R, et al. Chemistry and properties of nanocrystals of different shapes. Chem Rev, 2005, 105: 1025-1102

7 Tao AR, Habas S, Yang P. Shape control of colloidal metal nanocrystals. Small, 2008, 4: 310-325

8 Hong JW, Kang SW, Choi BS, et al. Controlled synthesis of Pd-Pt alloy hollow nanostructures with enhanced catalytic activities for oxygen reduction. ACS Nano, 2012, 6: 2410-2419

9 Sun Y. Shape-controlled synthesis of gold and silver nanoparticles. Science, 2002, 298: 2176-2179

10 Wu J, Pan YT, Su D, et al. Ultrathin and stable AgAu alloy nanowires. Sci China Mater, 2015, 58: 595-602

11 Liang HP, Zhang HM, Hu JS, et al. Pt hollow nanospheres: facile synthesis and enhanced electrocatalysts. Angew Chem Int Ed, 2004, 43: 1540-1543

12 Chen C, Kang Y, Huo Z, et al. Highly crystalline multimetallic nanoframes with three-dimensional electrocatalytic surfaces. Science, 2014, 343: 1339-1343

13 Liang HW, Liu JW, Qian HS, et al. Multiplex templating process in one-dimensional nanoscale: controllable synthesis, macroscopic assemblies, and applications. Acc Chem Res, 2013, 46: 1450-1461 
14 Sun Y. Silver nanowires-unique templates for functional nanostructures. Nanoscale, 2010, 2: 1626

15 Wang JL, Liu JW, Lu BZ, et al. Recycling nanowire templates for multiplex templating synthesis: a green and sustainable strategy. Chem Eur J, 2015, 21: 4935-4939

16 Sun Y, Mayers BT, Xia Y. Template-engaged replacement reaction: a one-step approach to the large-scale synthesis of metal nanostructures with hollow interiors. Nano Lett, 2002, 2: 481-485

17 GS, Cao, YC, Jin, R, Mirkin, CA. Triangular Nanoframes Made of Gold and Silver. Nano Lett, 2003, 3: 519-522 doi: 10.1021/nl034097+

18 Chen Z, Waje M, Li W, et al. Supportless Pt and PtPd nanotubes as electrocatalysts for oxygen-reduction reactions. Angew Chem, 2007, 119: 4138-4141

19 Lu Y, Chen W. Nanoneedle-covered Pd-Ag nanotubes: high electrocatalytic activity for formic acid oxidation. J Phys Chem C, 2010, 114: $21190-21200$

20 Chen L, Kuai L, Yu X, et al. Advanced catalytic performance of Au-Pt double-walled nanotubes and their fabrication through galvanic replacement reaction. Chem Eur J, 2013, 19: 11753-11758

21 Polavarapu L, Liz-marzán LM. Growth and galvanic replacement of silver nanocubes in organic media. Nanoscale, 2013, 5: 4355-4361

22 Shahjamali MM, Bosman M, Cao S, et al. Surfactant-free sub-2 nm ultrathin triangular gold nanoframes. Small, 2013, 9: 2880-2886

23 Popa A, Samia ACS. Effect of metal precursor on the growth and electrochemical sensing properties of Pt-Ag nanoboxes. Chem Commun, 2014, 50: 7295-7298

24 Yang Y, Zhang Q, Fu ZW, et al. Transformation of Ag nanocubes into Ag-Au hollow nanostructures with enriched Ag contents to improve SERS activity and chemical stability. ACS Appl Mater Interfaces, 2014, 6: 3750-3757

25 Jing H, Wang H. Structural evolution of Ag-Pd bimetallic nanoparticles through controlled galvanic replacement: effects of mild reducing agents. Chem Mater, 2015, 27: 2172-2180

26 Li J, Liu J, Yang Y, et al. Bifunctional Ag@Pd-Ag nanocubes for highly sensitive monitoring of catalytic reactions by surface-enhanced Raman spectroscopy. J Am Chem Soc, 2015, 137: 7039-7042

27 Sciacca B, Yalcin AO, Garnett EC. Transformation of Ag nanowires into semiconducting $\mathrm{AgFeS}_{2}$ nanowires. J Am Chem Soc, 2015 137: 4340-4343

28 Wiley B, Sun Y, Mayers B, et al. Shape-controlled synthesis of metal nanostructures: the case of silver. Chem Eur J, 2005, 11: 454-463

29 Siekkinen AR, Mclellan JM, Chen J, et al. Rapid synthesis of small silver nanocubes by mediating polyol reduction with a trace amount of sodium sulfide or sodium hydrosulfide. Chem Phys Lett, 2006, 432: 491-496

30 Yang C, Gu H, Lin W, et al. Silver nanowires: from scalable synthesis to recyclable foldable electronics. Adv Mater, 2011, 23: 3052-3056

31 Zeng J, Tao J, Li W, et al. A mechanistic study on the formation of silver nanoplates in the presence of silver seeds and citric acid or citrate ions. Chem Asian J, 2011, 6: 376-379

$32 \mathrm{Au} \mathrm{L}, \mathrm{Lu}$ X, Xia Y. A comparative study of galvanic replacement reactions involving $\mathrm{Ag}$ nanocubes and $\mathrm{AuCl}_{2}{ }^{-}$or $\mathrm{AuCl}_{4}{ }^{-}$. $\mathrm{Adv}$ Mater, 2008, 20: 2517-2522

33 Alia SM, Zhang G, Kisailus D, et al. Porous platinum nanotubes for oxygen reduction and methanol oxidation reactions. Adv Funct Mater, 2010, 20: 3742-3746

34 Sun Y, Xia Y. Mechanistic study on the replacement reaction between silver nanostructures and chloroauric acid in aqueous medium. J Am Chem Soc, 2004, 126: 3892-3901

35 Sun Y, Xia Y. Triangular nanoplates of silver: synthesis, characterization, and use as sacrificial templates for generating triangular nanorings of gold. Adv Mater, 2003, 15: 695-699

36 Wang Z, Liu J, Chen X, et al. A simple hydrothermal route to largescale synthesis of uniform silver nanowires. Chem Eur J, 2005, 11: 160-163

37 Xia X, Wang Y, Ruditskiy A, et al. 25th anniversary article: galvanic replacement: a simple and versatile route to hollow nanostructures with tunable and well-controlled properties. Adv Mater, 2013, 25: 6313-6333

38 Sun Y, Gates B, Mayers B, et al. Crystalline silver nanowires by soft solution processing. Nano Lett, 2002, 2: 165-168

39 Xia Y, Yang P, Sun Y, et al. One-dimensional nanostructures: synthesis, characterization, and applications. Adv Mater, 2003, 15: 353-389

40 Ma L, Huang Z, Duan Y, et al. Optically active chiral Ag nanowires. Sci China Mater, 2015, 58: 441-446

41 Yin Y, Lu Y, Sun Y, Xia Y. Silver nanowires can be directly coated with amorphous silica to generate well-controlled coaxial nanocables of silver/silica. Nano Lett, 2002, 2: 427-430

42 Scardaci V, Coull R, Lyons PE, et al. Spray deposition of highly transparent, low-resistance networks of silver nanowires over large areas. Small, 2011, 7: 2621-2628

Acknowledgments This work was supported by the National Natural Science Foundation of China (21431006), the Foundation for Innovative Research Groups of the National Natural Science Foundation of China (21521001), the National Basic Research Program of China (2014CB931800 and 2013CB931800), the Users with Excellence and Scientific Research Grant of Hefei Science Center of Chinese Academy of Sciences (CAS) (2015HSC-UE007 and 2015SRG-HSC038), and the CAS (KJZD-EW-M01-1).

Author contributions Wang JL and Wang $\mathrm{ZH}$ performed the experiments; Wang JL wrote the paper with support from Liu JW. Yu $\mathrm{SH}$ supervised the projects and carefully reviewed and modified this manuscript. All authors contributed to the general discussion.

Conflict of interest The authors declare that they have no conflict of interest.

Supplementary information Supporting information is available in the online version of the paper. 

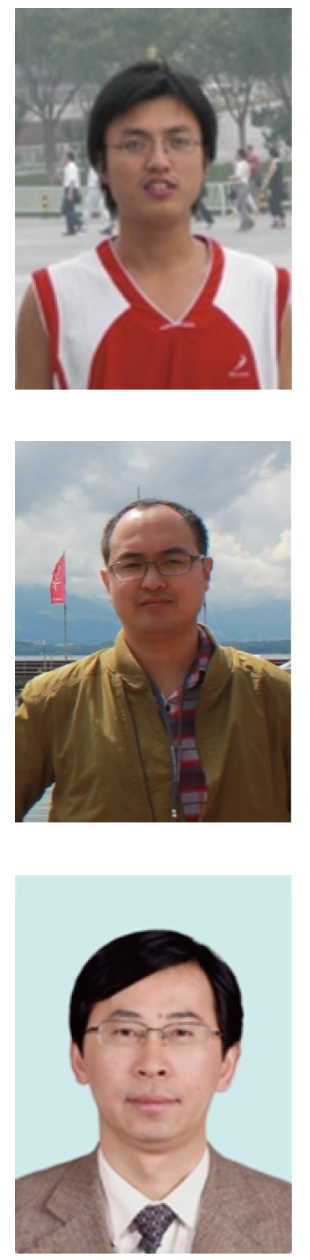

Jin-Long Wang received his bachelor degree majored in material chemistry from China University of Petroleum in 2011. Then he joined the University of Science and Technology of China and conducted research under the supervision of Prof. Shu-Hong Yu. His research interest is to recycle the valuable products from waste in chemical synthesis.

Jian-Wei Liu received his BSc degree majored in chemical engineering and technology from Hefei University of Technology in 2007, and his PhD degree in nano-chemistry under the supervision of Prof. Shu-Hong Yu from the University of Science and Technology of China. He is interested in the synthesis and self-assembly of one dimensional nanomaterials as well as nano-device fabrication based on well aligned nanowires.

Shu-Hong Yu received his BSc at Hefei University of Technology and his PhD degree (inorganic chemistry) from the University of Science and Technology of China (USTC). He was a postdoctoral fellow with M. Yoshimura (Tokyo Institute of Technology) and a Humboldt Fellow with M. Antonietti and H. Cölfen (MPI of Colloids and Interfaces, Germany). In 2002, he was appointed the Cheung Kong Professor at USTC. Currently, he leads the Division of Nanomaterials \& Chemistry at the Hefei National Laboratory for Physical Sciences at Microscale, USTC. His current research interests include bio-inspired synthesis and self-assembly of new nanostructured materials and nanocomposites, and their related properties. He serves as an editorial advisory board member of journals Accounts of Chemical Research, Chemistry of Materials, Chemical Science, Materials Horizons, Nano Research, ChemNanoMat, CrystEngComm, Part. Part. Syst. Charact. and Current Nanoscience. His recent awards include Chem. Soc. Rev. Emerging Investigator Award (2010) and Roy-Somiya Medal of the International Solvothermal and Hydrothermal Association (ISHA) (2010).

\section{多种纳米模板反应中高价值银的回收与重复利用}

王金龙, 王智华, 刘建伟*, 俞书宏*

摘要 利用银纳米材料的反应活性, 通过模板反应可以制备形貌和结构可控的多种金属纳米结构, 然而, 在模板反应过程中, 银纳米模板剂 通常被氧化成银离子作为副产物被遗弃. 考虑到金属纳米结构具有的广泛应用前景, 以银为模板剂大规模制备各种金属纳米结构过程中 的成本和环境问题必须予以关注. 为了解决这个问题, 我们对此类模板反应过程中所产生的废弃副产物氯化银进行了回收, 并以此为原料 成功的制备出高质量的银纳米线. 以模板反应制备金/铂纳米结构为例, 银的平均回收率可达到 $69.8 \%$ $84.6 \%$. 此外, 利用废弃副产物重新合 成的银纳米线具有均一的尺寸分布, 在模板反应和制备透明导电电极方面表现出优异的化学和物理性能. 